Fixed Point Theory, 22(2021), No. 2, 837-854

DOI: $10.24193 /$ fpt-ro.2021.2.54

http://www.math.ubbcluj.ro/ nodeacj/sfptcj.html

\title{
WEAK ASYMPTOTIC STABILITY FOR SEMILINEAR FRACTIONAL DIFFERENTIAL EQUATIONS WITH FINITE DELAYS
}

\author{
NGUYEN NHU QUAN \\ Department of Mathematics, Electric Power University, \\ 235 Hoang Quoc Viet, Hanoi, Vietnam \\ E-mail: quan2n@epu.edu.vn
}

\begin{abstract}
This paper investigates a class of semilinear fractional differential equations with finite delays. Based on the $\alpha$-resolvent theory, the fixed point theory for condensing maps and the local estimates of solutions, we prove the existence of solutions to the suggested system when the nonlinear part is superlinear. In the case, the nonlinear part is sublinear we study the weak asymptotic stability of the zero solution by applying a new Halanay type inequality. An application to a class of partial differential equations will be given.
\end{abstract}

Key Words and Phrases: Weak asymptotic stability, Halanay inequality, measure of noncompactness, condensing map.

2020 Mathematics Subject Classification: 35B35, 37C75, 47H08, 47H10.

Acknowledgment. The author would like to thank the referees for their constructive comments and suggestions which have greatly improved this paper.

\section{REFERENCES}

[1] R.R. Akhmerov, M.I. Kamenskii, A.S. Potapov, A.E. Rodkina, B.N. Sadovskii, Measures of Noncompactness and Condensing Operators, Birkhäuser, Boston-Basel-Berlin, 1992.

[2] C.T. Anh, T.D. Ke, On nonlocal problems for retarded fractional differential equations in Banach spaces, Fixed Point Theory, 15(2014), 373-392.

[3] N.T. Anh, T.D. Ke, Decay integral solutions for neutral fractional differential equations with infinite delays, Math. Methods Appl. Sci., 38(2015), 1601-1622.

[4] N.T. Anh, T.D. Ke, N.N. Quan, weak stability for integro-differential inclusions of diffusionwave type involving infinite delays, Discrete Contin. Dyn. Syst. Ser. B, 21(2016), 3637-3654.

[5] W. Arendt, P. Bénilan, Wiener regularity and heat semigroups on spaces of continuous functions, in: Topics in Nonlinear Analysis, Progress in Nonlinear Differential Equations Application, vol. 35 (Birkhäuser, Basel, 1999), pp. 29-49.

[6] A. Haraux, M.A. Jendoubi, The Convergence Problem for Dissipative Autonomous Systems. Classical Methods and Recent Advances, Springer Cham - Heidelberg - New York - Dordrecht London, 2015.

[7] M. Kamenskii, V. Obukhovskii, G. Petrosyan, J.C. Yao, Boundary value problems for semilinear differential inclusions of fractional order in a Banach space, Appl. Anal., 97(2018), no. 4, 571591. 
[8] M. Kamenskii, V. Obukhovskii, P. Zecca, Condensing Multivalued Maps and Semilinear Differential Inclusions in Banach Spaces, de Gruyter Series in Nonlinear Analysis and Applications, vol. 7, Walter de Gruyter, Berlin, New York, 2001.

[9] T.D. Ke, D. Lan, Decay integral solutions for a class of impulsive fractional differential equations in Banach spaces, Fract. Calc. Appl. Anal., 17(2014), no. 1, 96-121.

[10] T.D. Ke, D. Lan, Fixed point approach for weakly asymptotic stability of fractional differential inclusions involving impulsive effects, J. Fixed Point Theory Appl., 19(2017), 2185-2208.

[11] T.D. Ke, N.N. Quan, Finite-time attractivity for semilinear tempered fractional wave equations, Fractional Calculus and Applied Analysis, 21(6)(2018), 1471-1492.

[12] J. Kemppainen, J. Siljander, V. Vergara, R. Zacher, Decay estimates for time-fractional and other non-local in time subdiffusion equations in $R^{d}$, Math. Ann., 366(2016), 941-979.

[13] Y.-N. Li, H.-R. Sun, Z.S. Feng, Fractional abstract Cauchy problem with order $\alpha \in(1,2)$, Dynamics of PDE, 13(2016), 155-177.

[14] V. Vergara, R. Zacher, Optimal decay estimates for time-fractional and other nonlocal subdiffusion equations via energy methods, SIAM J. Math. Anal., 47(2015), 210-239.

[15] I.I. Vrabie, $C_{0}$-Semigroups and Applications, North-Holland Publishing Co., Amsterdam, 2003.

[16] R.-N. Wang, D.-H. Chena, T.-J. Xiao, Abstract fractional Cauchy problems with almost sectorial operators, J. Differential Equations, 252(2012), 202-235.

[17] D. Wang, A. Xiao, H. Liu, Dissipativity and stability analysis for fractional functional differential equations, Fract. Calc. Appl. Anal., 18(2015), no. 6, 1399-1422.

[18] H. Ye, J. Gao, Y. Ding, A generalized Gronwall inequality and its application to a fractional differential equation, J. Math. Anal. Appl., 328(2007), 1075-1081.

[19] Y. Zhou, F. Jiao, Existence of mild solutions for fractional neutral evolution equations, Comput. Math. Appl., 59(2010), 1063-1077.

Received: January 7, 2020; Accepted: May 29, 2020. 
